IIUC STUDIES

ISSN 1813-7733

Vol.- 7, December 2010

(Published in December 2011) (p 179-196)

\title{
Teaching -Learning Situation of Speaking in English at the University Level: A Case Study
}

\author{
Md. Iqbal Hosain ${ }^{*}$
}

\begin{abstract}
This paper intends to find out the problems that the students face in speaking in English at the different universities in Bangladesh. It investigates the merits and demerits of the existing teaching methodology of English at the university level. With a view to finding out the causes of the students' lack of competence in speaking in English, some authentic data have been collected from the different universities of the country. And after a thorough analysis, a suggestion has been made for teachers to use some pragmatic ways of improving speaking skills in English. It further examines the different techniques of teaching speaking in English at the university level along with its curriculum and testing system, and offers some easy and modern methods of teaching English.
\end{abstract}

\section{Introduction}

\subsection{English in Bangladesh}

After the partition of India and Pakistan in 1947 on the basis of twonation theory of Jinnah and later on the emergence of Bangladesh as a sovereign country, English has been an important medium of instructions in the administrative and the political system of the subcontinent. Even the conservative Muslims were learning English with enthusiasm. But the language policies adopted in Bangladesh, including the Language Act of 1987, have been characterized by a

\footnotetext{
* Lecturer, Department of English Language and Literature, IIUC, Dhaka Campus.
} 
stress on 'Bengali in all spheres; which in turn has stood in the way of using English in the different domains of Bangladeshi life and cultures. This effect is especially seen in the four main formal domains of Bangladeshi life: administration, education, law and the media. (Banu \& Sussex 1999, p122)

The education sector was greatly affected by this policy especially at the primary and secondary levels. All the English medium schools were abolished in 1972. (Banu \& Sussex 1999, p126)

However, it was not possible to ban English from the universities of the country. It is difficult to predict the future of English in Bangladesh. It is true that both from linguistic and literary point of view, the English language has contributed substantially to the language of Bangladesh and has also been influenced by the sociolinguistic setting. Finally, English has made a room in the mind of the people as a prestigious means of communication.

\subsection{Circumstances of Spoken English in Bangladesh}

Speaking is one of the productive skills, which is the evidence of a student that how much he or she is competent in a language. Moreover, much of the communication is made through speaking. In short, learning a language remains incomplete if one does not achieve competence in speaking.

In Bangladesh students are required to read English at the primary, secondary, and higher secondary levels for about twelve years. But their level of proficiency is below the mark. (Sadruddin, 2010 p252) They enter universities for undergraduate programs with a low proficiency in English. After completing the graduate and postgraduate levels, they have to enter the job market. In different interviews they are tested on their competence in English, but the results are often disappointing. Moreover, most of the graduate and postgraduate students are not capable of speaking good English, which is an evidence of one's competence in a language. What is the reason behind it? Obviously, there is something wrong in the method of teaching and learning. At the university level, especially at private universities, the students usually forget what they have learned at secondary and higher secondary levels as most of the departments, except the English Department, do not take proper care of developing the students' skills of speaking in English. Although English is the prime subject of the English Department, most of the English 
Departments of different private and public universities prefer literature to language.

However, the universities of Bangladesh are now-a-days trying to improve the condition of English. What is the present condition of English at the university level, and how are they going on with their strategies to promote English language skills?

\subsection{English at the Universities of Bangladesh}

Although English is a global language, and we have been speaking it since the country was a British colony, we are not learning English in a proper way. In the context of Bangladesh, English is taught from the elementary level to the university level. The time span being fifteen years, the outcome is not satisfactory. A minute observation has revealed that various techniques are followed at the university level to teach English; among them the Grammar Translation Method is worth mentioning. Recently, the well accepted Communicative Language Teaching has been adopted, especially at the Secondary and Higher Secondary levels. But no specific method and curriculum are followed at the university level. Hence, the output varies from one university to another university. And the performance of the students is very poor.

In most of the universities of the country, English has been included in the first year or first semester except in the English Department, and the students somehow attend the class and collect necessary suggestions to obtain pass marks in English. After finishing the first year, they usually forget what they have learned. Another problem is with the syllabus and the course contents. Most of the items in the syllabus are based on different grammatical items, which make the students feel bored in learning English.

\subsection{Research Questions}

1. What are the reasons that make the students reluctant to speak English at the university level?

2. What method is followed at the university level?

3. What are the limitations at university level in teaching and learning spoken English?

4. What measures should be taken at the university level to promote students' speaking skills? 


\subsection{Hypothesis}

i. As many teachers are incompetent, they find themselves reluctant to speak English in the class. This creates passivity among the students and they feel discouraged to speak in English.

ii. As communication is made in Bengali medium, the students get accustomed to communicating in Bengali. In fact, the environment is not favorable and so the students feel ashamed to speak in English outside the class.

iii. Prejudices sometimes stand in the way of speaking in English. Even some English knowing people believe that speaking in English in the class is some sort of flamboyance. They argue in favour of decolonizing Bengali mentality to upgrade the image of the mother tongue. They sometimes refer to the great sacrifice of language martyrs.

iv. To enhance speaking ability, listening to the native English movies, news channels is necessary. But well-equipped language lab facilities are not available in most of the universities.

v. Testing system is not conducive to the development of speaking skills. The traditional system of testing is still in vogue at many universities. This system encourages students to cram notes rather than to study for achieving competence in speaking.

vi. Students depend on memorization as their teachers provide suggestions in the class. The final target of the students is to pass the examination, not to achieve competence in speaking.

\section{Literature Review}

\subsection{What is speaking?}

In language teaching, the four skills are described in terms of their direction. Language generated by the learner in speech or writing is referred to as productive, i.e. speaking and writing are considered as productive skills. On the other hand reading and writing are considered as receptive skills. Another important idea is the channel, which refers to the medium of the message (aural/oral or written). Thus, speaking is the productive aural/ oral skill (Nunan 2003, p48). It consists of producing systematic verbal utterances to convey meaning. 


\subsection{Elements of Spoken English}

The teaching of foreign language has traditionally concentrated on making the student aware of certain aspects of the code (vocabulary of foreign language, phonological and morphological features, and syntactic rules) without providing adequate practice in the selection of a message and in the process of encoding it for transmission. As a result, after years of study students have known a great deal about a foreign language without being able to use it to express their intention. Rivers (1968:p159-160) has outlined some elements of speaking skill conducive to L2 learners. These are discussed below:

\section{a. Use of Dialogues}

Use of dialogues can promote students' speaking skills to a great extent. Different situations can be offered to the student through dialogues, which is really conducive to them. Rivers says "Many a student well trained in manipulation of language structures has found himself completely at a loss in conducting a conversation with native speaker of the language because the books from which he (and his teacher before him) learned the language forms failed to emphasize the characteristic features of everyday spoken language and persistently used archaic or pedantic turns of phrases." (Rivers 1968: p167-68)

\section{b. The Audio-visual Approach}

Some teachers firmly advocate the use of some form of audio-visual aid in the teaching of speaking, especially in the early stages. Because the audio-visual approach helps the students promote speaking skills. Rivers says," In its simplest form the audio-visual approach has been employed for many years in classroom where objects, pictures, actions, and gestures have been systematically used with aural-oral work to elucidate meaning... advocates of an audio-visual approach put forward several reasons for considering the visual element essential to the efficient learning and speaking".(Rivers1968,p.175)

\section{c. Conversation Groups and Foreign Language Clubs}

Rivers emphasizes on forming conversation groups and foreign language club in order to promote speaking skill. He says," More intensive practice in the art of conversation can be provided, at the advanced level, in small groups meeting together at regular intervals". (Rivers: 1968, p.202-205)

Foreign language clubs can also help promote speaking ability of L2 learners as there is interaction between the learners. Speaking ability 
can also be developed in foreign language club, where students are forced into an effort at communication in an informal atmosphere. (Rivers: 1968)

\subsection{Teachers' Objective of Teaching English as a Foreign Language}

A language teacher, according to Rivers, should have the following objectives in the teaching of a foreign language:

a. To develop students' intellectual powers through foreign-language study;

b. To increase students' personal culture through the study of the great literature and philosophy;

c. To increase students' understanding of how language functions and to bring him, through the study of foreign language, to a greater awareness of the functioning of his own language;

d. To provide the student with skills which enable him to communicate orally, and to some degree in writing, with the speakers of another language and with people of other nationalities who have also learned this language;

\subsection{Principles for Teaching Speaking}

\section{a. Giving students practice with both fluency and accuracy}

In accordance with Nunan (2003, p55), accuracy is the extent to which students' speeches match what people actually say when they use the target language. Fluency is the extent to which speakers use the language quickly and confidently, with few hesitations or unnatural pauses, false start, word searches, etc.

\section{b. Providing Opportunities for students to talk by using group work or pair work, and limited teacher talk}

Teacher should be careful about the participation of the student in the class. He or she should encourage the student to speak in the class and provide opportunities for them so that they may feel free to speak ignoring limitations. Nunan (2003) has pointed out referring the result of a research: "...teachers do approximately 50 to 80 percent of the talking in classroom".(p55)

He further suggested that pair work and group work activities can be used to increase the amount of time that learners get to speak in the target language during lessons. One further interesting point is that when the teacher is removed from the conversation, the learners take 
on diverse speaking roles that are normally filled by the teacher such as posing questions or offering clarification (Nunan 2003, p.55).

\section{c. Designing class activities that involve guidance and practice in both transactional and intersectional speaking}

When we talk with someone outside the classroom, we usually do so for interactional or transactional purposes. Interactional speech is communicating with someone for social purposes. It includes both establishing and maintaining social relationships. Transactional speech involves communicating to get something done, including the exchange of goods and /or services.

Most spoken interactions "can be placed on a continuum from relatively unpredictable" (Nunan1991, p.42). Conversations are relatively unpredictable and can range over many topics, with the participants taking turns and commenting freely. In contrast, Nunan states that "transactional encounters of a fairly restricted kind will usually contain highly predictable patterns" (1991, p.42) and he gives the example of telephoning for a taxi.

He further says that interactional speech is much more fluid and unpredictable than transactional speech. Speaking inside the classroom need to embody both interactional and transactional purposes, since language learners will have to speak the target language in both transactional and intersectional settings.

\section{Fluency}

Hedge (2000) defines it as the ability to respond coherently within the turn of conversation, to link the words and phrases of the questions, to pronounce the sounds clearly with appropriate stress and intonation and to all these quickly in 'real time' (Johnson 1979). And it is called 'fluency'. Hedge (2000) also includes fluency as a component of communicative competence.

In the classroom, particularly grammatical errors are tolerated during fluency-based activities. However, it does not mean that CLT does not aim for a high standard of formal correctness. According to Larsen-Freeman (2000), the teacher will note the errors during fluency activities and return to the learners later with an accuracybased activity. 


\subsection{Role of Communicative Language Teaching in developing speaking skill}

Communicative Language Teaching claims to develop the ability of learners to use language in real communication. Brown and Yule (1983) characterize communication as involving two general purposes -the interactional function, where language is used referentially to exchange information. CLT, then, is directed at enabling learners to function interactionally and transactionally in second language. The distinction between a weak and a strong version of CLT parallels the distinction between task-supported language teaching and task-based language teaching.

\section{Research Methodology}

This research attempts to find out the real causes of the students' lack of competence in speaking in English at the university level. With a view to unearthing the reasons, the researcher collected data from different universities situated in the Dhaka city. To serve the purpose, the researcher prepared some questionnaires for both teachers and students, and supplied those questions to them for their opinions regarding the problems. The researcher further interviewed the teachers and the students. He also minutely observed some English classes to have the real scenario of English teaching.

\subsection{Data Presentation and Analysis Data Collection}

To conduct the survey, data were collected from different universities of Dhaka city. The following were the sample instruments for collecting and handling the data regarding the issue:

\section{a. Subjects}

The subjects of this research were 79 students who filled the questionnaires supplied by the researcher. Teachers also filled up the questionnaires. Most of the students were from different social backgrounds. Some are from elite class families, some from middle class families, and some from lower middle class families.

\section{b) Data}

Both qualitative and quantitative data were collected for this research. Questionnaires for teachers and students, observation checklists, syllabuses, question papers prepared for Semester Final Examination were the elements used for conducting the research. (See Appendices) 


\subsection{Data Collecting Procedure}

Most of the questions in the questionnaires were multiple choice questions. These questions were basically on the classroom environment, teaching methodology, syllabus and materials and regarding the competence and the performance of the teachers. The researcher thought that they would be helpful to get an idea of the attitude and the feelings of both the teachers and the students about the problems of speaking in English at the university level. The teachers were observed while conducting the classes, and were also interviewed on different aspects of English teaching and learning at the universities. A well- planned observation checklist was followed to analyze the performance of the teachers. The teachers were not allowed to stay in the classroom during the students' filling up the questionnaire so that the students could freely respond to the questions.

\subsection{Data Analyzing Procedure}

Basically the nature of this study is similar to those of a descriptive study. Considering this fact, the survey method was chosen for this empirical study. Three main techniques of the survey method are: Questionnaire survey for teachers and students, classroom observation and the interviews with the teachers and the students. Therefore, the data were collected from: 1) Students' Questionnaires, 2) Questionnaires for teachers, and 3) classroom observation.

The researcher analyzed the data both in qualitative and in quantitative way. In accordance with Ellis (1991), this is a 'hybrid research'. The researcher kept the following things in mind while collecting data:

i. if the environment is congenial to the teaching and learning of speaking in English;

ii. if the teachers use English as a medium of instructions;

iii. if the students feel like speaking;

iv. if the syllabus is eligible for the students;

\subsection{Reasons for Selecting the Areas}

The researcher visited five universities, each of which is situated in Dhaka city. The main reason for selecting the universities in Dhaka is that most of them are well-established and well-reputed. Therefore, the classroom activities of these universities are supposed to be standard. The five universities are ASA University, United International 
University, University of Liberal Arts, International Islamic University Dhaka Campus and Bangladesh Islami University.

\section{Results of the Empirical Study}

\subsection{Students' Interview}

Ten students were interviewed on the different issues related to the English teaching and learning situation at the university level. They have individually put their opinions on the issues. The main aspects of their opinions are as follows:

i. Almost all the teachers conduct their classes in English.

ii. Almost all the teachers encourage them to speak in English.

iii. They do not speak English to their classmates always.

iv. They are not always able to speak in English in every situation.

v. They think that their syllabus is not supportive to promote their skills speaking in English.

vi. Most of the universities do not have lab facilities.

vii. Teachers are not competent enough to teach English language.

viii. The teachers are always reluctant to speak in English.

ix. Extra curricular activities are not adequately organized to improve the speaking skills.

x. Finally, the environments are not favorable for practicing English.

\subsection{Teachers' Interview}

Ten teachers of the five universities were interviewed. Their opinions are as follows:

i. Teacher-student relationship is not supportive. Sometimes the teachers are too much frank, and sometimes they are too much reserved.

ii. CLT is not followed at almost all the universities.

iii. Grammar based teaching is still dominant at the university level.

iv. Due to poor salary, teachers are not much caring to their students. Somehow they finish the syllabus and provide suggestions for the students. They look for part-time jobs at other universities for earning more money. 
v. Students are always careful of passing the examination rather than of achieving competence in speaking English.

\subsection{Report on Class Observation}

Five classes of teachers at the five universities were observed. The following findings came out from the classroom observation:

i. Most of the observed teachers found coming into the class without lesson plans.

ii. Only two teachers were found methodically lecturing in the class.

iii. Their lecture was quite audible to the last bench.

iv. Three teachers were found interacting with the students.

v. Two of the classes were on presentation.

vi. Most of them were timely present in the class.

\subsection{Result of the Students' Questionnaire}

The first question was: Do you speak English in the class?

Result: Yes: $47.37 \%$ NO: $7.65 \% \quad$ Sometimes: $44.98 \%$

The second question was: Do you feel comfortable in speaking in English?

Result: Yes: $56.70 \% \quad$ No: $16.22 \% \quad$ Sometimes: $30.31 \%$

The third question was: Do you like the way in which you are taught speaking English?

Result: Yes: $73.84 \% \quad$ No: $12.40 \% \quad$ Sometimes: $22.31 \%$

The fourth question was: Do your teachers encourage you to practice speaking in English in the classroom?

Result: Yes: $94.94 \% \quad$ No: $2.98 \% \quad$ Sometimes: $3.33 \%$

The fifth question was: Can you speak on any relevant topic easily?

Result: Yes: $29.26 \% \quad$ No: $11.15 \% \quad$ Sometimes: $56.91 \%$

The sixth question was: Do you think that your teachers are relaxed in teaching you speaking?

Result: Yes: $64.91 \% \quad$ No: $24.74 \% \quad$ Sometimes: $14.29 \%$

The seventh question was: How rich is your English vocabulary?

Result: Rich: $7.71 \% \quad$ Moderate: $78.45 \% \quad$ Poor: $13.28 \%$

The eighth question was: How fluent are you in speaking in English?

Result: Good: $56.63 \%$ Very Good: $1.33 \%$ Not Satisfactory: $42.02 \%$ 
The ninth question was: Do you have sufficient command over the necessary sentence structures for speaking in English?

Result: Sufficient: $59.96 \%$ Insufficient: $25.54 \%$

Not Satisfactory: $24.49 \%$

The tenth question was: Can you ask question in correct form?

Result: Yes: $46.59 \% \quad$ No: $2.38 \% \quad$ Sometimes: $51.10 \%$

The eleventh question was: Can you continue a conversation easily in English in any situation?

Result: Yes: $24.49 \% \quad$ No: $64.49 \% \quad$ Sometimes: $59.01 \%$

The twelfth question was: Do you think that your English teachers are competent in teaching you speaking English?

Result: Yes: $94.66 \%$ No: 5.33

The thirteenth question was: Do your teachers use different situations to converse in English?

Result: Yes: $73.12 \% \quad$ No: $11.15 \% \quad$ Sometimes: $15.71 \%$

The fourteenth question was: Do you have any language lab in your university?

Result: Yes: $41.43 \% \quad$ No: $52.56 \% \quad$ Sometimes:

The fifteenth question was: Do you practice conversation in English with your classmates?

Result: Yes: $47.65 \% \quad$ No: $18.59 \% \quad$ Sometimes: $32.7 \%$

The sixteenth question was: Do your teachers encourage you watching English programs on TV?

Result: Yes: $77.61 \% \quad$ No: $9.33 \% \quad$ Sometimes: $13.05 \%$

The seventeenth question is: Do your teachers encourage you listening to radio for improving English pronunciation?

Result: Yes: $66.52 \% \quad$ No: $16.49 \% \quad$ Sometimes: $16.98 \%$

The eighteenth question was: Do you read any English books?

Result: Yes: $51.93 \% \quad$ No: $10.03 \% \quad$ Sometimes: $38.09 \%$

The nineteenth question was: Do you have any prejudice against speaking in English?

Result: Yes: $30.53 \% \quad$ No: $69.47 \%$

The twentieth question was: Do you think whether your English now better than it was at the college?

Result: Yes: $77.47 \% \quad$ No: $12 \%$ 


\section{$\underline{\text { Result of Questionnaire for Teachers }}$}

Question No 01: Do you use English as a medium of instruction in the classroom?

\begin{tabular}{|c|c|c|}
\hline Yes & No & Sometimes \\
\hline $100 \%$ & & \\
\hline
\end{tabular}

Question No 02: Do you think grammar is essential for speaking in English?

\begin{tabular}{|c|c|c|}
\hline Yes & No & Sometimes \\
\hline $83.34 \%$ & & $16.66 \%$ \\
\hline
\end{tabular}

Question No 03: Do you encourage your students to speak in English in the class and outside the class?

\begin{tabular}{|c|c|c|}
\hline Yes & No & Sometimes \\
\hline $100 \%$ & & \\
\hline
\end{tabular}

Question No 04: Are you free and frank with your students in the class?

\begin{tabular}{|l|l|l|}
\hline Yes & No & Sometimes \\
\hline $100 \%$ & & \\
\hline
\end{tabular}

Question No 05: Are you strict about the mistakes of your students in the class?

\begin{tabular}{|c|c|c|}
\hline Yes & No & Sometimes \\
\hline $33.34 \%$ & $50 \%$ & $16.66 \%$ \\
\hline
\end{tabular}

Question No 06: How important do you think is the need for your students' speaking in English?

\begin{tabular}{|c|c|c|}
\hline Very Important & Important & Not so Important \\
\hline $83.34 \%$ & $16.66 \%$ & \\
\hline
\end{tabular}

Question No 07: What is the main problem of your students in speaking in English at university level?

\begin{tabular}{|c|c|c|c|}
\hline $\begin{array}{c}\text { Lack of } \\
\text { competence }\end{array}$ & Shyness & $\begin{array}{c}\text { Insufficient } \\
\text { Vocabulary }\end{array}$ & All of These \\
\hline $16.66 \%$ & $16.66 \%$ & & $66.66 \%$ \\
\hline
\end{tabular}


Question No 08: How can you create opportunities for your students to speak better English?

\begin{tabular}{|c|l|l|l|}
\hline $\begin{array}{c}\text { By Arranging } \\
\text { Pair works }\end{array}$ & $\begin{array}{l}\text { Offering } \\
\text { Varieties of } \\
\text { Situations }\end{array}$ & $\begin{array}{l}\text { By Organizing } \\
\text { Debate }\end{array}$ & All of These \\
\hline & $16.66 \%$ & $83.34 \%$ & \\
\hline
\end{tabular}

Question No 09: How do you encourage your students to speak in English?

\begin{tabular}{|c|c|c|c|}
\hline $\begin{array}{c}\text { Creating } \\
\text { Sense of } \\
\text { Confidence }\end{array}$ & Practicing & $\begin{array}{c}\text { Making Them } \\
\text { Feel at Ease }\end{array}$ & All of These \\
\hline $16.66 \%$ & & $1.66 \%$ & $66.66 \%$ \\
\hline
\end{tabular}

\section{Findings}

In the whole of the study procedure, the researcher minutely observed several factors related to teaching and learning English at the university level in Bangladesh. In addition, the researcher also tried to learn about the teaching methods, teaching materials, classroom situations, learners' expectations and a few other related things. The following findings resulted from the empirical investigation:

\subsection{Findings regarding the students}

i. Most students think that English is a difficult subject.

ii. The existing syllabus is not supportive to the improvement of the skills in speaking in English.

iii. Almost all the teachers found disinclined in conducting their classes in English.

iv. Teachers are not caring much to the development of students' skills in English.

v. Most students feel shy in speaking in English in the class and outside the class.

vi. Extra-curricular activities such as debate in English, recitation, set speech etc. are not usually organized by the authorities of the university. 
vii. Traditional testing system, with a focus on achievement rather than on performance, is not supportive to promote students' speaking skill.

viii. Most of the universities have no lab facilities for promoting students' skills in speaking in English.

ix. Some students and teachers found to have prejudice against English. They think that to speak here and there is the flamboyancy and the colonial mentality of the individuals.

\subsection{Findings regarding the teachers}

i. Most of the teachers are not well-trained.

ii. They are dissatisfied with the students' performance.

iii. Almost all of them do not use English as a medium of instructions.

iv. They think grammar is essential to achieve competence in English.

v. Though they encourage the students to speak in English outside the class, they do not.

vi. According to the teachers, the main problems of the students in speaking in English are as follows:

a. lack of practice, shyness, insufficient command of vocabulary; and necessary sentence structures;

\subsection{Suggestions given by the teachers:}

Ten teachers were interviewed. They put forward the following suggestions:

i. The student should be encouraged to speak in English at home and university with teachers and friends.

ii. Listening to and watching programs in English on Radio and Television should be encouraged.

iii. The student should read English newspapers and magazines regularly.

iv. If possible, students should try to make friendship with native speakers.

v. The teacher has to be very friendly with the students and encourage them to speak in English. 
vi. The student should be given assignment for presentation on various topics so that they can overcome shyness in speaking in English.

vii. Higher authorities along with the teachers should motivate the students to speak in English on the campus.

viii. Every university should have language laboratory with modern equipment.

ix. Continuous motivation, practice and development of a sense of confidence may facilitate the students to overcome the problems in speaking in English.

x. Course materials to be participatory in nature for both the teachers and the students.

\section{Conclusion}

In this research, I have studied and observed the problems of the students in speaking in English at the university level in Bangladesh. I have also learned about the teaching methods, teaching and learning materials, classroom situations, learners' expectations and teachers' expectations.

I started my research with four questions. They were related to (i) the students' reluctance in spoken English, (ii) methodology of teaching speaking English, (iii)limitations of the universities and (iv) remedial measures for the problems in speaking English. As answers to those questions, I found the following reasons: a) the reason of the students' reluctance in spoken English is that the environments are not favorable, b) the method of teaching is neither Communicative Language Teaching nor Grammar Translation, c) universities are unable to provide modern facilities.

To overcome the problems identified in the research, some pragmatic steps should be taken. The researcher recommends the following remedial measures to be taken to overcome the problems:

\subsection{Steps to be taken by the Teachers}

While teaching in the classroom, the teachers should use English as medium of instruction and involve the students in various types of language tasks and activities in groups or pairs to help them learn English through constant skill practice. They should also encourage their students to actively participate in the learning process. 
Furthermore, they should monitor and assist their students while they are engaged in skill practice. Besides, they should emphasize both accuracy and fluency at the time of teaching speaking in English. Finally, the teachers should adopt the modern communicative techniques in teaching speaking in the classroom.

\subsection{Test Reform}

In Bangladesh, the examination system is more product-oriented rather than process-oriented, leading to an emphasis on grades than performance. A few teachers in the interview suggested for changing the examination system, including 'speaking test'. (Li:1998, p13) Definitely, unless the examination system is changed, the competence level of the students will remain stagnant.

\subsection{Reduction of class size}

According to Halliday (1994), the communicative approach is often rejected for a big classroom. It is difficult to manage a huge class of 40 or 50 students. The growing population of Bangladesh has created a huge pressure, especially on the public universities and on some of the private universities. It causes difficulties for the teachers to meet the demand of every student in the limited class time. Therefore, the size of the classroom should be reduced to a small one which can accommodate 20 to 25 students.

\section{$\underline{\text { Works Cited }}$}

Ahmed, S. Learning English The Easy Way. Dhaka: Friends' Book Corner, 2010.

Banu, R and R.Sussex,. Who's Centric Now? The Present State of PostColonial Englishes, Melbourn: Oxford University Press, 1999.

Brown, G.\&Yule, G.TeachingtheSpokenLanguage.Cambridge:Cambridge University Press, 1983

Ellis, R. The study of Second language Acquisition. Oxford: Oxford University Press, 1994. Press, 1991

SLA Research and Language Teaching. Oxford: Oxford University

Halliday, A. Appropriate Methodology. Cambridge: Cambridge University Press, 1994. 
Hedge, T. Teaching and Learning in the Language Classroom. Oxford: Oxford University Press, 2000

Johnson. The Communicative Approach to Language Teaching, Oxford: Oxford University Press, 1979.

Larsen-Freeman, D. Techniques and Principles in Language Teaching. $2^{\text {nd }}$ ed. Oxford: Oxford University Press, 2000

Li, D. "It's Always More Difficult Than You Plan and Imagine": Teachers' Perceived Difficulties in Introducing the Communicative Approach in South Korea, TESOL Quarterly, Vol 32, NO 4. 1998

Rivers, Wilge M. Teaching Foreign- Language Skills. London: The University Chicago Press, 1968

Nunan, D. Language Teaching Methodology: A Textbook for Teachers London: Prentice Hall, 1991. 2003. . Practical English Language Teaching. New York: McGraw-Hill, 